\title{
Prof. Alberto Amaral
}

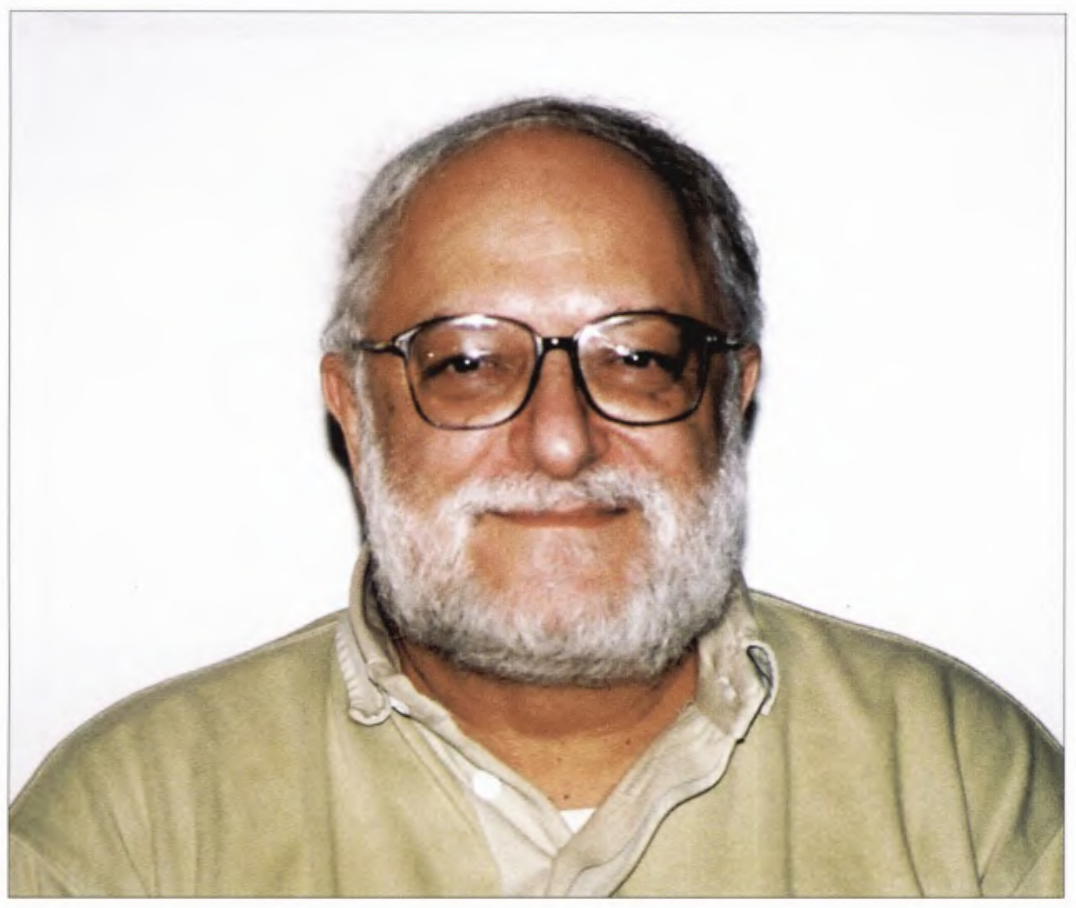

O Professor Alberto Amaral, recebeu-nos no CIPES em pleno Matosinhos, num edifício antigo, bem apresentado, com o excelente metro de superfície à porta. Numa cidade onde a meio da tarde se viam pessoas no café em frente, sentadas nas mesas em tranquila conversa, fazendo lembrar um tempo onde as pessoas falavam umas com as outras e se conheciam nos cafés. Um tempo que ainda resiste nalguns locais, uma certa tranquilidade e qualidade de vida que vai durar até quando?

Fez a sua licenciatura em Engenharia Químico-Industrial, na Faculdade de Engenharia do Porto, em Julho de 1965. Porque razão escolheu a Química, ou melhor a Engenharia Química?

Havia um meu avô que era médico e a minha avó queria um descendente que Ihe seguisse as pisadas; andava sempre ainda está na Faculdade de Ciências, decidimos seguir a Engenharia Química. Não houve assim nenhumas razões de peso; gostava de coisas de laboratório, mexia em bichos. Quando era miúdo abria toupeiras e coisas do género, até que me fartei daquela existência dirigida para a medicina, e enveredei pela Engenharia Química.

$O$ período da sua licenciatura foi marcado pela crise académica de 62 . Como viveu essa crise?

Foi com um certo divertimento; Portugal atravessava um período complicado, as pessoas hoje, pelo menos os jovens, já não têm a percepção do que foi. 0 centro principal das atenções foi Coimbra e um bocado o Técnico, no Porto foi algo mais contido. Mas que abalou um bocado a instituição.

Creio que a Faculdade de Letras tinha sido recentemente reaberta ${ }^{1}$ ?

Sim, sim. A Faculdade de Letras do Porto tem um passado histórico muito complicado, a Faculdade de Letras foi extinta por um ministro. Será restabelecida mais tarde, mas viverá sempre no terror de poder ser extinta uma segunda vez. É algo que pesava na consciência dos professores.

Mas a crise académica de 62 teve algo a ver com a sua tomada de consciência política, ou passou-lhe ao lado?

Concerteza que sim. Não só isso como depois o período em que estive em Cambridge, em Inglaterra.

Tendo acabado a sua licenciatura em 1965, em 1968, encontramo-lo com o doutoramento feito em Cambridge. 
Trata-se de um período muito curto para os padrões da época?

Em Janeiro de 66 fui para Inglaterra trabalhar numa área que não era laboratorial; doutorei-me em Química Quântica, e acho que isso poderá ter tido alguma influência, porque era algo que não estava dependente do sucesso laboratorial, mas meramente do trabalho de computador. Isso permitiu fazer o doutoramento com uma certa rapidez. Por outro lado, também é verdade que, naquela altura, nós com os 3 anos da Faculdade de Ciências tinhamos uma preparaçăo teórica muito boa. ${ }^{2}$ A minha preparação em termos de Matemática, Física, Química era claramente superior à dos meus colegas Ingleses.

\section{Já tinha uma posição de assistente quando foi para Cambridge?}

Não, não; porque devido exactamente a esses períodos da crise académica, houve uma recusa em contratarem-me devido à minha posição algo contestatária. Eu fui para Inglaterra meramente como particular, com uma bolsa. E sem qualquer ligação contratual à Universidade. Fui contratado quando regressei.

E como foi o seu contacto lá em Inglaterra? O seu supervisor foi o Professor Linnett.

Sim o contacto foi feito por professores; havia professores da Faculdade (nomeadamente o Professor João Cabral) que me apoiaram e me ajudaram, inclusivamente a obter a bolsa de estudos.

E escolheu logo a Química Quântica e aquele laboratório em particular?

Escolhi a Química Quântica porque enfim, dentro do nosso Departamento de Química, houve uma certa orientação sobre em que áreas apostar; e nessa altura a área que me propuseram foi da Química Quântica, que eu achei interesante e que me entusiasmou; a ideia original não era que eu fosse trabalhar com o Linnett, mas sim com um indivíduo muito conhecido na altura que era o Longuet-Higgens; nessa altura, o Linnett ainda estava em Oxford. O Longuet-Higgens escreveu-me uma carta a dizer que, em boa verdade gostaria de ser supervisor mas que iria mudar para
Edimburgo, para fazer investigaçāo numa área completamente diferente, cibernértica/inteligência artificial; e portanto recomendou-me que esperasse pela vinda do Linnett para Cambridge.

Sai do Porto na ressaca da crise académica e vai para Cambridge. O que é que sentiu quando chegou a Inglaterra um País com liberdade, como é que isso o marcou?

Marcou muito. Há uma situação que eu nunca esqueço. Uma vez eu estava em Londres, e havia uma manifestação, na Trafalgar Square, de um conhecido nazi, o Moseley, um Inglês meio nobre, e havia um grupo grande de Judeus que faziam uma contra-manifestação. E a polícia estava lá para proteger o nazi...enfim as pessoas tinham liberdade de falar enquanto não pertubassem a ordem pública, tinham direitos. Foi uma coisa que a mim, habituado ao velho Portugal, me marcou imenso; a liberdade de expressão, os direitos das pessoas, os tribunais a funcionar (uma coisa que nós ainda não temos não é...), eficazes e a actuar a tempo e horas.

No regresso, a minha mulher estava grávida do meu primeiro filho e não podia vir de avião, e viemos de barco. Vínhamos de barco em direcção a Espanha quando numa manhã metem o jornal de bordo por baixo da porta, e o jornal de bordo anunciava exactamente que o Salazar tinha caído da cadeira: abrimos uma garrafa de champanhe!...risos. Nunca mais me esqueci desse episódio, na vinda de barco, em pleno oceano, recebermos a noticia que "o Senhor" tinha deslizado da cadeira para baixo.

Do ponto de vista científico como era o ambiente cultural? Discutia muito com os seus colegas?

Era um sítio extraordinário, porque a grande ênfase de Cambridge é na investigação e no desenvolvimento pessoal. Cambridge era uma das Universidades onde se preparavam os quadros do Império, toda a ênfase era posta naquilo que nós faziamos por nós próprios. E havia de facto grandes debates. A própria união de estudantes organizava um debate semanal muito interessante, para criar nas pessoas o hábito de discutir; havia sempre um tema, para o qual eram contactados dois individuos de ideias perfeitamente opostas. Um debate a que assisti tinha por tema "todos os Deuses são redundantes", e os convidados foram o Arcebispo de Cantuária e um notório ateu. Isto criava todo um ambiente de facto extraordinário, porque não havia meramente a questão da aprendizagem, havia também a formação das pessoas; as pessoas eram formadas como gentleman e a pior coisa que se podia fazer era cometer um acto que não fosse digno de um gentleman. Ai uma pessoa estava de facto marcada.

E quais eram os actos não dignos de um gentleman?

...risos. Por exemplo aldrabar, cometer uma incorreção social grave. Mas era de facto um ambiente extraordinário. Havia facilidades enormes na investigação.

\section{E quando voltou?}

Tinha o serviço militar. Adiei aquilo até perto dos trinta anos, e em 72 acabei por achar melhor ir para Moçambique. $\mathrm{Na}$ altura era possivel ser requisitado pela Universidade. E passei quatro anos em Moçambique durante os quais fiz o serviço militar.

Então conheceu o Professor Sousa Lobo em Moçambique?

Sim.

É curioso porque ele afirmou, na entrevista anterior, que o Maio de 68 passou ao lado de Inglaterra. Concorda com esta afirmação dele?

Sim, sim! é curioso que o Maio de 68 de facto não se fez sentir em Inglaterra. Aqui há tempos, há uns três ou quatro anos atrás, participei num exercício engraçado. Fiz parte da equipa que fez a acreditação periódica da Universidade de Columbia em Nova lorque; e notei, o que é muito curioso, que o Maio de 68 ainda está presente nas pessoas. 0 Maio de 68 teve uma importância maior. estranhamente, numa universidade americana em Nova lorque do que teve em Inglaterra, em particular em Cambridge. Ou, pelo contrário, até talvez natural porque os problemas que levaram 
ao Maio de 68 em França, não existiam em Inglaterra.

Pertence a uma numerosa geração de Químicos que rumaram a Inglaterra para fazer o doutoramento. É um movimento que aconteceu em Lisboa, no Porto e em Coimbra. Porque razão Inglaterra e não outro qualquer País, como França, Alemanha, Estados Unidos, ou mesmo Itália?

Sim havia razōes. Por um lado pela boa reputação das Universidades em Inglaterra. Depois porque era um processo que estava bem estabelecido. Sabia-se que eram três anos no máximo quatro, as coisas funcionavam normalmente. 0 caso Francês era complicado, porque havia uma confusão entre os dois tipos de doutoramento; o caso alemão estava de lado porque as pessoas não falavam alemão, nos Estados Unidos o caso também estava praticamente arrumado porque era muito caro e era bem mais longo. Do lado do Estado Português houve claramente um beneficio da solução inglesa, até porque o Veiga Simão, que na altura era ministro, tinha sido doutorado em Inglaterra; e uma boa parte dos professores que na altura estavam doutorados, ainda que em Engenharia, tinham de facto sido doutorados em Inglaterra. Pelo meu lado tendo um processo de serviço militar à frente, convinha-me também algo que nâo fosse demasiado longo porque depois podia vir a ter problemas. Mas as estatísticas estão aí. Acho que cerca de 75 por cento dos jovens académicos que se foram doutorar na área da Ciência e Tecnologia o fizeram na Inglaterra. Ao contrário das áreas das letras e das Ciências Sociais em que foram para França

No seu curriculum abreviado não consta nenhuma publicação em Química. No entanto trabalhou e publicou com o Prof. Linnet, um Químico de grande envergadura. Será que quer apagar a Química da sua vida?

Nāo. De maneira geral os curricula que me pedem são curricula para coisas actuais, e neste momento eu não faço Química. Num curriculum resumido não vou buscar as coisas que fiz há quinze ou vinte anos atrás, mas as dos últimos quatro cinco anos. Eé essa a razão.

Então porque é que abandonou a Química principalmente numa área tão estimulante como a que investigava?

Por uma razão simples. Porque depois de 12 anos de Reitor em que estive praticamente afastado da investigação em Química Quântica, seria extremamente difícil regressar. Eu tinha perdido muito tempo.

Mas vinha de uma Química teórica que não necessita de tanta infra-estrutura de laboratório...

Sim mas as coisas mudam completamente, e eu estive completamente afastado do meio. Por outro lado, durante o periodo que estive na Reitoria, tive um grande interesse pelo desenvolvimento de matérias ligadas às politicas do ensino superior. Tive alguns amigos meus estrangeiros que começaram de certo modo a convidar-me para este tipo de actividades. Aliás o Reitor de uma Universidade Holandesa, que na altura dirigia um centro de política do ensino superior, teve uma grande influência na minha viragem para essa área. Convidou-me para fazer várias conferências e era uma área nova. Também é verdade que eu nunca tive a ideia de que uma pessoa deva estar muito tempo na mesma coisa. Comecei pela Engenharia Química, depois passei para a Química...

Mas esteve numa área extremamente aliciante, o estudo da estructura electrónica.

Já foi mais aliciante...

Uma área a que foi atribuído o prémio Nobel ainda em 1998?!

Acho que a Química Quântica ou a Mecânica Quântica foi aliciante nos anos vinte e trinta, quando de certo modo toda a Física foi formulada e era uma grande novidade. Acho que depois a partir dos anos setenta, começou muito a mastigar. Mais computador, menos computador, mais algoritmo menos algortimo, o algoritmo dos algoritmos! para mim as coisas perderam o seu fascínio.
Tenho aqui uma sua citação, que foi escrita para comentar os ranking das escolas." As medidas anteriores que visavam a criação de uma escola inclusiva, uma escola aberta a todos, símbolo de um sistema que favorece a mobilidade social e a igualização dos cidadãos, passaram agora a ser atacadas em nome da defesa e promoção da qualidade do ensino, se necessário com recurso à substituição progressiva das inovações pedagógicas por pedagogias tradicionais reinventadas (os exames, os procedimentos disciplinares, os chumbos, etc.)." Estas suas palavras não correm o risco de ser interpretadas como a defesa de um nivelamento por baixo?

É evidente, quando se tira alguma coisa fora do contexto, não se pode perceber...

Mas todo o seu artigo parecia reflectir este sentir.

Não há dúvida nenhuma que o caso dos Estados Unidos é um caso óbvio, em que a Universidade funciona em muitos casos (e não é só a universidade), como um instrumento perpetuante da sociedade de classes. No fim de contas só vai para uma grande Universidade privada americana, ou quem tem dinheiro, ou uma determinada percentagem de alunos de carácter excepcional que lá consegue chegar, mas a generalidade da população não tem qualquer possibilidade de lá chegar. Por outro lado, na Europa, durante as últimas décadas houve uma enorme ênfase no usar o ensino como factor de promoção social. 0 acesso para todos, o ensino secundário para todos, o ensino superior para todos, e isso hoje começa a ser posto em causa. E porque é que começa a ser posto em causa? Porque de repente as classes mais favorecidas notaram que afinal aquela tal licenciatura já não dava direito aos filhinhos de terem o tacho garantido nos sítios devidos. E portanto há que retomar, ou que recriar as vantagens de classe. E só conseguem recriar as vantagens de classe, tornando a criar um ranking de instituiçōes. De um lado os bons Colégios para onde irão os seus filhos, do outro a escola de não sei de onde para onde irá o filho do padeiro, e depois por ai acima. A sociedade terá de pensar então o que é que pretende. 
Mas não precisamos de gente bem preparada e qualificada? e a Universidade não a poderá formar?

Sim sim, pois pode. Mas não tem nada que ver com esta coisa do ranking. Que é a coisa mais estúpida que se pode imaginar. Eu não admito um ranking das escolas secundárias sem ter em conta todos os outros factores que the estão associados. Uma escola no Casal Ventoso, nunca será uma escola das primeiras do ranking, onde quer que seja. Asneira será penalizar essa escola, e os professores, que se calhar até sāo muito mais dedicados do que aqueles que trabalham na escola dos meninos da Foz.

Isto no caso do ensino secundário, mas um ranking universitário?

0 ranking universitário,... também ai tenho as minhas dúvidas.

Precisamos ou não de gente qualificada e bem preparada?

Isso nẫo tem nada a ver com os rankings.

\section{Precisamos de boas universidades?}

Isso sim!

Faz muito melhor, mais bem ao ensino, ter uma universidade que por exemplo siga os padrões da Universidade de Columbia (NY), que tivesse excelência como padrão absoluto, e em que, quem não for excelente, o professor, o investigador, vai para o olho da rua! o que nós năo fazemos. Isso faz muito melhor à qualidade do que fazer o ranking. 0 ranking não é algo que contribuia para a qualidade.

\section{Mas toda a gente sabe que Cambridge era uma Universidade excelente e pro- vavelmente continua a ser uma Uni- versidade excelente.}

Era e é, mas isso é por outra razão. 0 padrão de qualidade das aulas de Cambridge era horroroso.

\section{$\mathrm{Na}$ altura?}

Na altura e agora. É uma Universidade de elite. A função da Universidade não é dar a papa aos meninos nas aulas. Cada dois alunos tinham um tutor, porque 0 tutor mandava os meninos irem para a biblioteca fazer trabalho, a ideia era desenvolver a capacidade de um individuo saber por si. O professor dizia eu sou um investigador e venho para aqui uma hora aturar estes tipos. A qualidade das aulas de uma maneira geral era má. Era má e eram poucas, quer dizer. Havia três trimestres, só havia aulas teóricas no primeiro e segundo trimestre; cada trimestre tinha dezasseis aulas, o resto era trabalho pessoal.

O grande drama hoje é que nós temos as universidades que se massificaram, não há hoje dentro do País universidades de elite. Ora não se ensina da mesma maneira um aluno de elite e um aluno de massas.

Essa é uma das áreas de interesse aqui do CIPES ${ }^{3}$, os desafios da massificação. Quais são esses desafios?

O grande problema da massificação é o da Universidade não se ter adaptado a isso. Nós continuamos a olhar para os nossos alunos e a dizer que estão mal preparados; continuamos a ignorar que, quando temos um ensino massificado, uma porção muito grande dos alunos tem de ter um acompanhamento muito mais completo, e mais intenso do que o de um aluno numa Universidade de elite; se calhar as Universidades deveriam preocupar-se em homogeneizar os alunos à entrada, vendo quais são as deficiências deles. Nós continuámos como professores universitários, e eu próprio a mim me acuso, a pensar que se 0 aluno é adulto deverá trabalhar por si, que se desenrasque! e isto não funciona numa universidade de massas, em Cambridge sim.

Então sugere que haja diversos tipos de universidades, uma para as elites...

Exactamente. Não é possivel nenhum País ter dinheiro para ter ensino superior com investigação em termos de um sistema massificado. Não tem dinheiro nem interessa. Porque uma grande massa de alunos que hoje chegam ao ensino superior não quer um ensino de elite. Quer é uma coisa que the dê uma profissão. Nem sequer fazer uma carreira de investigação. Nem todos, se caIhar, querem um grande desenvolvimento teórico nas aulas.
Então como é que proporia essa diversificação do ensino superior?

Como em Inglaterra, universidades que de facto são conhecidas a nivel mundial e que só têm alunos de excepção, Oxford, Cambridge, etc, e as outras que depois ensinam o resto da população.

\section{E nós temos possibilidade de ter isso} aqui em Portugal?

Só teremos isso se tivermos a coragem em deixar que uma ou duas sejam e as outras não. Claro,...risos.... esse é o problema. Em Inglaterra não é preciso nehum ranking para saber que Oxford $\mathrm{e}$ Cambridge são excelentes e que a Universidade Oxford-Brooks, um antigo Politécnico promovido, é uma outra coisa completamente diferente

Portanto acha que há necessidade de nós termos também este tipo de estratégia?

Se nós queremos que em Portugal haja uma ou duas instituições com capacidade de competir a nivel internacional, essa é a única possibilidade; não se pode andar a dizer que todos os Politécnicos, todas as Universidades vão fazer investigação. Não dá, onde é que têm dinheiro para isso? onde é que têm pessoas? Nenhum País tem. Nos Estados Unidos em que há três mil e não sei quantas instituiçōes de ensino superior, há cento e poucas Universidades de investigação. Claro que depois poderemos ter outros problemas como os de justiça social, etc., mas terão de ser resolvidos de outra forma.

\section{Acha que podemos ter uma boa gestão sem ter uma boa política para o Ensino Superior?}

Não ligaria em excesso as duas coisas. $\mathrm{O}$ que uma pessoa tem de perceber é que estamos numa fase, não é só uma fase em Portugal, também noutros países europeus e nomeadamente em Inglaterra, onde há uma emergência de políticas de pendor neoliberal. Que põe uma grande ênfase na eficácia e eficiência económica das instituições, o que leva a por em causa os modelos tradicionais de gestão das instituições universitárias. Será que um Reitor é um bom gestor ou é preciso ir buscar um 
tipo à Sonae? A minha opinião é que uma Universidade de excelência não pode ser gerida como uma empresa, não tem nada a ver uma coisa com a outra. Até porque uma Universidade de Excelência é uma universidade onde se faz inovação. E a inovação está ligada a outra coisa, está ligada à transgressão. As grandes descobertas da Física, a Mecânica Quântica a Teoria da Relatividade etc, foram transgressões enormes em relação às teorias científicas aceites. Se calhar numa universidade muito regulada, empresarial, esse tipo de descoberta nunca teria sido possivel.

\section{Porque não há desperdício?}

Exactamente, a capacidade de inovação da universidade está também muito ligada a um certo desperdício, à possibilidade de uma pessoa poder fazer coisas malucas, durante cinco anos aquilo não dá nada mas um dia...E isso não é possivel numa instituição que seja gerida como uma empresa.

\section{Mas nos Estados Unidos as melhores universidades serão por certo inovado- ras e são privadas. Como o explica?}

Não pode comparar os Estados Unidos, com a sua cultura muito específica, com os outros países. Quando fui fazer a acreditação da Universidade de Columbia em Nova lorque, eles tinham terminado uma operação de recolha de fundos que em dois anos thes deu cerca de dois biliões de dólares, cerca de $400 \mathrm{mi}$ Ihões de contos; isto em dádivas! eu se for pedir dinheiro aqui, aos nossos antigos alunos, riem-se-me na cara...risos. Isto funciona nos Estados Unidos, mas não nos outros países. Acho que não se devem importar modelos. Assim como não podemos importar o modelo do privado americano para a Europa. Porque o que aconteceu nos Estados Unidos foi que todas as primeiras instituiçōes do ensino superior, todas as grandes instituições, eram todas privadas. Só apareceram instituiçōes públicas depois das instituiçōes privadas. Por isso são instituições que mantiveram uma longa tradição de qualidade. As privadas aqui na Europa são meras operações comerciais. Mesmo assim nas grandes instituições americanas o que há é uma tradi- ção da profissionalização do gestor académico. O presidente de uma universidade americana é escolhido pelas suas qualidades, mas é um individuo que não é um empresário, é um académico que é treinado como gestor; eles mudam de universidade para universidade, têm as suas carreiras. Embora haja recentemente uma crítica quanto à profissionalização das universidades americanas. Há um livro que foi escrito por um individuo chamado Charles Smith, que é da universidade de Nova Iorque, onde se chama a atenção para que em muitos sítios o que aconteceu foi, ao irem buscar não o presidente académico, mas o gestor profissional, as pessoas se esqueceram de uma coisa: é que dentro das universidades há um número enorme de horas de trabalho que são feitas voluntariamente pelos docentes e sem custos. Presidentes do Conselho Cientifico, Directivo e Pedagógico, membros do Senado, etc. O trabatho que isso dá em termos de administração sendo feito voluntariamente, não tem encargos para a instituição. Quando surge o gestor profissional bem pago, as pessoas olham para o lado e pensam, então é o trabalho dele. E o gestor profissional, nos Estados Unidos, perdeu de repente o apoio dos académicos, e a solução foi reproduzir-se e criar uma estructura administrativa para substituir a falta de apoio do lado académico, e portanto isso gera este conflito entre os administadores e os académicos; o que em boa verdade acabou por resultar num aumento dos encargos da gestão para substituir o trabalho voluntário que desapareceu. Todos nós queremos que as instituições sejam bem geridas. Só um estúpido é que não quer isso. Mas gerir bem uma instituição universitária não tem nada a ver com gerir uma fábrica de salsichas ou de parafusos ou, o que quer que seja. É uma coisa completamente diferente.

Estava a dizer que para as universidades de excelência não poderiamos ter um gestor tipo Sonae, mas para as outras?

Deixe-me dar-Ihe um exemplo. A minha querida universidade de Cambridge, em boa verdade é governada por uma coisa chamada Regents House onde se sentam três mil professores; sempre que há uma decisão da administração central e isso dura há vários anos - sempre que há uma ideia ao nível central de profissionalizar a gestão, como bastam cinco assinaturas para levar essa decisão ao Regents House, a universidade vota sempre conta, em nome da defesa dos valores académicos. E a Universidade de Cambridge continua a ser boa. Mas se calhar não é gerida pelos padrões de economia e de eficiência que um empresário poderia escolher.

Em relação aos acordos de Bolonha, quais acha que serão as consequências da sua aplicação, pensa que haverá uma profunda re-estruturação do nosso ensino superior?

Eu sou um céptico dos acordos de Bolonha. Acho que os acordos de Bologna não fazem muito sentido, quando durante muito tempo se fez a defesa que uma das riquezas das universidades europeias era a diversidade dos seus sistemas de ensino. Temo que os acordos de Bolonha possam acabar, ou poderiam acabar, numa grande uniformização a nivel europeu. Mas não vai acontecer. Estou convencido que os acordos de Bologna nầo vão chegar ao fim. Há uma propaganda, um marketing, em torno de Bolonha de que está tudo a correr sob esferas. Mas isso não corresponde há realidade.

\section{Mas afirma-se que se deseja preservar a diversidade.}

Se analisar o que está a acontecer nos diversos países verá uma outra realidade. Eu neste momento estou a fazer um trabalho com um grupo de investigadores internacionais e financiado pelo governo Italiano, o qual pretende nomeadamente analisar 0 estado de implementação do processo de Bolonha; tivemos recentemente uma reuniẫo em Milâo, onde se concluiu que, por exemplo, na Alemanha só dois por cento dos alunos é que estão em cursos compatíveis com o processo de Bolonha. Porque o governo permite estarem os dois sistemas a funcionar em paralelo, numa mesma Universidade, e estas 
preferem o sistema tradicional ao método Bolonhês.

\section{Os italianos também têm os dois siste- mas a funcionar em paralelo?}

Exactamente, e em França também, onde há mais de dez mil nomes diferentes de cursos. 0 que acontece é que as instituições têm os dois sistemas a funcionar em paralelo. Isto de Bolonha é mais algo que está a ser empurrado, de cima, do que propriamente algo em que as instituições estejam convictamente envolvidas. Se ler a lei portuguesa, ou a proposta que está na Assembleia da República o que é que diz? Em princípio é de quatro, mas pode ser de cinco ou pode ser de seis. 0 mestrado pode ser de um ano ou pode ser de dois. Pode-se juntar o primeiro ao segundo ciclo que pode ser de cinco anos, ou três mais um ou quatro mais dois.

Mas há países em que a tendência é encurtar um pouco o primeiro ciclo.

Mas está na lei que pode ser quatro anos.

0 primeiro acordo assinado, na Sorbonne, é conhecido como o Viagra dos ministros fracos...risos. Porque havia três ministros que estavam com problemas em casa, a França a Itália e a Alemanha, e conjuntamente com a Iglaterra assinaram aquilo; o Inglês assinou porque julgou que era como o sistema inglês e achou piada ver os franceses e os alemães a assinarem aquilo; e os outros porque precisavam da desculpa europeia para implementar aquilo em casa.

Mas a nova Ministra da Educação italiana já disse que vai permitir coisas que nada têm a ver com Bolonha. Portanto eu não sei o que isto vai dar. Mas também é possivel olhar para o processo de Bologna como uma forma de desresponsabilizar financeiramente o.governo em relação ao ensino superior. Não sendo fácil na maioria dos países europeus impor as propinas, se calhar é possível reduzir os compromissos do Estado diminuindo a duração dos estudos. Porque ao fim de três anos, se você tem o primeiro ciclo, pode, em teoria, ir trabaIhar; o conceito de emprego foi substituido pelo conceito de empregabilidade, se vier a ser desempregado, o problema é seu. Para se manter "empregável" vai fazer pós-graduaçōes, e vai pagá-las. É uma desresponsabilização do Estado.

Mas acha então que os três anos não são suficientes para termos um ensino superior ou pelo menos uma formação de qualidade?

Três anos não são suficientes, não.

E em relação ao sistema europeu de créditos?

Isso não aquece nem arrefece.

Mas será uma vantagem, uma vez que permite uma circulação dos estudantes mais fácil?

Acha que sim? Deixe-me dizer uma coisa. $\mathrm{O}$ que é ridículo no meio disto tudo é que os alunos são cada vez menos móveis.

Se pensarmos que um semestre são trinta créditos, e que em vez de fazermos avaliação cadeira a cadeira podemos transferir o equivalente a um semestre?

Sobre isto estamos de acordo, mas o que é rídiculo é que o aluno é cada vez menos móvel.

\section{Porquê?}

Por um lado porque deixou de haver financiamento comunitário para a mobilidade; e também é menos móvel dentro dos próprios paises, como é o caso inglês, porque passaram a substituir as bolsas por empréstimos. Hoje a mobilidade em Inglaterra está a diminuir e está a diminuir de uma forma significativa, porque um aluno faz as contas e diz, se eu ficar em casa ao fim de quatro anos devo tanto, se eu mudo vou pagar mais, faz as contas e se calhar conclui que a dívida não compensa. Há um conjunto de politicas reais que são absolutamente contraditórias com a da mobilidade.

Então na sua opinião nós não precisávamos de nenhuma re-estruturação?

Há um colega meu que diz que, é um inglês aliás, a percentagem de alunos que é móvel na Europa é inferior à percentagem de alunos que era móvel na
Idade Média. Porque na Idade Média havia muito mais razōes para a mobilidade. As cadeiras eram todas iguais, em todas as faculdades o sistema de estudos era todo igual e a língua era a mesma. Havia muito mais uniformidade e, por haver poucas universidades, os alunos defendiam-se com a mobilida$\mathrm{de}^{4}$. Eu temo que se levassem o processo de Bolonha até às últimas consequências iríamos acabar num sistema muito mais homogeneizado do que o que temos hoje.

\section{E isso para si é uma desvantagem...?}

É e, aliás, toda a gente diz que é.

\section{Haveria mais mobilidade?}

Porquê? Para ir a outro lado ver uma coisa igual? A própria fase de homogeneizar acaba por destuir a mobilidade.

Foi Reitor da Universidade do Porto durante 13 anos. Num balanço de actividades há sempre um deve e um haver. Resumidamente, o que mudou para melhor, e o que ficou na mesma, ou eventualmente piorou, após os seus mandatos.

Acho que a universidade mudou significativamente. Mudou porque se tornou uma universidade com reconhecimento internacional, mudou porque foi uma época feliz em que havia dinheiro, e portanto fizeram-se investimentos enormes em matéria de equipamentos para ensino, em matéria de equipamentos para investigação. E mudou substancialmente porque em termos de investigação e de pós-graduação foram feitos progressos muito grandes. Também não havia a mania de que as universidades eram empresas; o que vai piorar neste momento são todas estas restições de natureza económica. Que, por sua vez, poderão provocar também uma desvalorização social dos diplomas universitários. Por outro lado, vai piorar o facto de no ensino superior não haver políticas coerentes, que não há.

Para si um Reitor pode condicionar a Universidade, isto é, ter um mau Reitor ou um bom Reitor pode ser crucial?

Sim sim, não só nisso. No período em que estive como Reitor, e não falo só de 
mim, falo de um conjunto de Reitores que havia no País, inclusivamente havia uma grande influência do conselho de Reitores na definição de políticas. Muitas leis que hoje estão aí publicadas, o financiamento, a avaliação, a flexibilidade de gestão das universidades, a própria lei da autonomia, feitas pelos Reitores antes do Governo. E hoje esse dinamismo perdeu-se e as pessoas agora em vez de tomarem a iniciativa aguardam pelas políticas ministriais; perdeu-se também muita coesão entre os membros do CRUP.

Não está de acordo com o ranking, mas quanto à avaliação da Universidade?

Eu devo dizer que sou das pessoas que mais trabalha em avaliação. Se olhar para aquilo que está aqui naquela parede são tudo avaliações internacionais.

\section{Mas avaliação não deve ser tornada pública?}

Sim, o que acho é que quanto mais trabalho nisso, mais cínico sou sobre os efeitos concretos da avaliação.

A avaliação dos nossos centros de investigação foi uma das coisas importantes feita pelo anterior Ministério da Ciência e Tecnologia e mantida pelo actual. Avaliar a produtividade científi$\mathrm{ca}$, ou o que quer que se define como produtividade científica. Houve muitas surpresas, boas e más.

Sim, não sei se foi feita da melhor maneira; mas a avaliação da investigação é muito mais fácil de fazer do que a do ensino. Aliás repare nenhum de nós jamais reagiu quanto tem os seus artigos avaliados pelos referees, sempre foram, e por isso está habituado a isso. No ensino os critérios são completamente diferentes.

Falou mesmo agora na desvalorização social dos diplomas universitários. Não há re-estruturação que possa inverter a situação?

Hoje o diploma universitário em si, e com a excepção de duas sou três áreas muito especiais, já não tem o valor que tinha antigamente; um canudo era um passaporte para o emprego, hoje não é nada.

Atendendo a que o diploma universitário vale pouco, acha que mesmo assim vale a pena fazer uma licenciatura e estudar Química em particular?

Sim vale porque quem não tiver uma licenciatura está bem mais tramado do que quem tiver uma!...risos

\section{Não é muito prometedor...}

Sabe porquê, porque na actual organização mundial da economia quem não tiver qualificações está feito...p porque o capital vai para onde for mais benéfico para ele, o que se mede como "onde os recursos forem mais baratos". A indústria têxtil portuguesa vai falir toda, e no calçado estão a ir uns atrás dos outros, porque se faz a mesma coisa mais barato na China; e um dia será mais barato em África. E quem diz disto diz do resto. Se a Ford-Volkswagen descobrir que é mais barato montar os monovolumes na República Checa, onde ainda são mais bem educados do que nós, e recebem menos, mudam para lá calmamente. E daí que a tal noção do emprego tenha desaparecido, a ideia é a de empregabilidade.

Hoje um jovem que tirou um curso e que se casou, pode dalí a cinco meses ou seis meses estar desempregado. Não tem estabilidade de trabalho, será que pode ter filhos?, é um risco muito grande. Tudo isto modifica dramaticamente a nossa sociedade. A minha esperança é que este modelo não seja estável. Porque, repare, há uma crise económica a nivel mundial, que apesar de todas as globalizações não está a diminuir, antes pelo contrário. Se calhar puseram os pobres tão pobres que agora não há quem compre o que se fabrica em excesso. No ciclo anterior, no período do Fordismo, o mecanismo baseava-se num circulo virtuoso, em que se procurava o emprego total; havia um estado providência que assegurava os grandes riscos como a saúde, dava subsídios de casa, de transportes, etc; e assim, a malta que trabalhava tinha dinheiro para comprar coisas. la alimentar esse ciclo. $E$ isto quebrou-se. Não sei se este modelo sobreviverá. Se calhar era bom que não sobrevivesse. Se comparar as estatísticas mundiais, verá que está a acontecer em todos os países, nomeadamente nos Estados Unidos, Inglaterra etc, um crescente aumento das desigualdades sociais.

\section{Poderá piorar ainda?}

Exactamente o que eu digo. Tenho até vergonha do mundo que vou deixar aos meus filhos e aos meus netos.

\section{Referências}

1 - A Faculdade de Letras da Universidade do Porto foi extinta pelo Decreto n. ${ }^{\circ} 15.365$, de 12 de Abril de 1928. Restaurada em 1961 pelo Decreto n. ${ }^{\circ} 43.864$, de 17 de Agosto, inicia as aulas no ano lectivo de 1962-1963 com duas licenciaturas, História e Filosofia, e o curso de Ciências Pedagógicas.

2 - Na altura, o curso de Engenharia Química consistia em 3 anos preparatórios leccionados na Faculdade de Ciências, com uma enorme carga em Matemática, Fisica e Quimica, seguidos de 3 anos na Faculdade de Engenharia, com uma componente mais técnica e aplicada.

3 - CIPES - Centro de Investigação de Políticas do Ensino Superior

4 - Esta situação começou a inverter-se quando o "príncipe" percebeu a importância da universidade e começou a criar universidades locais as quais muitas vezes foram protegidas proibindo os nacionais de se deslocarem para estudar no estrangeiro. Por exemplo, em Portugal, em 1440, o rei Afonso $\mathrm{V}$ deferiu uma petição dirigida às Cortes pela Universidade de Coimbra, na qual se pedia que todos os sủbditos com diplomas obtidos no estrangeiro tivessem que pagar 20 coroas à Universidade e fossem preteridos, a favor dos licenciados por Coimbra, nos concursos a empregos públicos. 


\section{Perfil Prof. Alberto Amaral}

Se tiver ocasiāo, procure no Departamento de Química de Cambridge a fotografia de grupo do ano de 1965/66. Procure o mais jovem e franzino dos fotografados. É o Alberto Amaral!

Com raizes em Fafe, Alberto Amaral fez os seus estudos no Porto, no então Liceu Nacional D. Manuel II, hoje dedicado de novo a Rodrigues de Freitas, e na Universidade do Porto. A Licenciatura em Engenharia Químico Industrial estava então organizada em seis anos, os três primeiros na Faculdade de Ciências, no velho edifício da Academia Real de Marinha e Comércio e da Academia Politécnica, e os últimos três anos na Faculdade de Engenharia, à Rua dos Bragas. Na Faculdade de Ciências, cobriam-se as bases de Matemática, Física e de Química a um nível muito respeitável mas algo irregular. Na Química pontificava a velha geração liderada por Alberto Brito e Mendonça Monteiro que tinha atravessado a profunda depressão económica e social subsequente à nossa participação na primeira Grande Guerra e depois a longuíssima "rectificação" financeira do Estado Novo. A iniciação dos futuros engenheiros era feita pela Química Inorgânica de Humberto Almeida, que passara pelos campos da Flandres e que, entre aulas no Colégio Almeida Garrett e assistência técnica ao Instituto do Vinho do Porto, se mantivera mais de 30 anos em posições juniores para só vir a chegar ao lugar de Professor Catedrático alguns anos mais tarde, nas vésperas da jubilação. Deste ambiente, Alberto Amaral recordará até hoje o método das câmaras de chumbo para a síntese do ácido sulfúrico que veio a ser o tema da última lição do velho mestre; terá visitado em Estarreja as fábricas de produção de adubos onde aquele método era usado. Fernando Serrão e João Cabral lutavam em condiçōes hoje inimagináveis para manter uma réstia de esperança e de actividade científica naquele ambiente de ensino livresco onde se podiam esperar de cada docente mais de trinta horas semanais de leccionação. Esta era a janela aberta para a modernidade que se foi depois progressivamente alargando e por onde Alberto Amaral saltou para Cambridge logo no termo da sua licenciatura, mesmo sem ter garantido 0 apoio financeiro...

Em Cambridge, trabalhou no desenvolvimento de métodos semi-empíricos sob a orientação de J. W. Linnett, um antigo aluno de Charles Coulson que estava então no topo da sua produtiva carreira. Em menos de três anos regressou ao Porto trazendo a sua juventude, o seu conhecimento pioneiro de Química Quântica, a sua excelente capacidade pedagógica e 0 seu inconformismo para uma Faculdade ainda moldada pelas suas graníticas paredes novecentistas. A sua publicação didáctica sobre as aplicações de teoria de grupos em Química foi pioneira em Portugal e circulou por longos anos. Não fui aluno de Alberto Amaral. Passei pela Faculdade de Ciências enquanto ele estava em Cambridge. Tive depois contacto com ele até ao jantar de despedida conjunto quando ele seguiu para a Universidade de Lourenço Marques (o Serviço Militar assim obrigava) e eu para Oxford em 1972. Reencontrei-o no regresso ao Porto que fizemos com 2 meses de diferença logo após a promulgação do decreto de Sottomayor Cardia sobre a gestão universitária. Partilhámos depois o gabinete vários anos quando o edifício dos Leões já rebentava por todas as costuras face ao rápido desenvolvimento do número de estudantes, do quadro docente e da investigação. Pouco tempo depois Alberto Amaral candidatou-se a Presidente do Conselho Directivo da Faculdade de Ciências, posição que só veio a abandonar quando assumiu a posição de Reitor da Universidade do Porto. A gestāo de Alberto Amaral no Departamento de Química, na Faculdade de Ciências e, depois, na Reitoria foi muito inovadora e transformou a instituição no que hoje conhecemos. Ainda no Departamento de Química, impulsionou o início da preparaçâo de doutoramento de uma série de jovens docentes o que veio a resultar no início da actividade de investigação regular, sistemática e com um ritmo que não cessou ainda de crescer. $\mathrm{Na} \mathrm{Fa}$ culdade de Ciências, teve um papel importante pela sua capacidade de intervenção no palco da política universitária e nos seus bastidores onde se iniciou. Foi nesta altura que tomou a iniciativa pessoal de preparar a construção do centro de cálculo da Universidade do Porto e dos departamentos de Química e de Física, lançando as bases do que é hoje o pólo dois da universidade no Campo Alegre. Como Reitor, iniciou uma nova era no exercício da função. Reorganizou profundamente todos os serviços da universidade, preparou os planos e começou o esforço de reinstalação das várias faculdades e liderou muitas das inovações da política universitária portuguesa nos últimos anos.

Terminados os seus mandatos de 14 anos, Alberto Amaral regressa à qualidade de simples professor da Universidade do Porto e à direcção do CIPES (Centro de Investigaçâo de Políticas do Ensino Superior ligado à FUP, Fundação das Universidades Portuguesas). É hoje uma personalidade muito destacada a nível europeu e com uma actividade bem reconhecida na área de investigação das políticas do ensino superior. Tem uma actividade muito intensa como consultor, como orador e como autor ou co-autor de grande número de publicaçōes. Nestas áreas, é, provavelmente, o perito português de maior impacto internacional. Entre nós tem actuado como consultor de sucessivos governos de cores diversas e a Missão de que está encarregado para a reforma dos estudos de saúde em Portugal tem tido um amplo reconhecimento e tem conseguido manter alguma estabilidade nesta área especialmente delicada pela gravidade dos problemas com que se debate, pela força dos interesses em jogo e pela importância e impacto das opçōes tomadas.

José Ferreira Gomes 